\title{
LA REVOCACIÓN DEL MANDATO EN LAS DEMOCRACIAS DE AMÉRICA LATINA
}

\author{
CARLOS GARRIDO LÓPEZ \\ Profesor Titular de Derecho Constitucional \\ Universidad de Zaragoza
}

TRC, n. ${ }^{\circ} 47,2021$, pp. 323-353

ISSN 1139-5583

\begin{abstract}
SUMARIO
I. La extensión de la revocación del mandato en las democracias latinoamericanas. II. La revocación del mandato de las autoridades locales en Colombia y Perú. III. La revocación del mandato en los entes federados y los municipios de Argentina y México. IV. La revocación en Panamá por decisión de los partidos políticos y por referéndum a iniciativa popular. V. La revocación del mandato de todos los cargos de elección popular en Ecuador, Venezuela y Bolivia: en especial, la revocación presidencial. VI. La revocación de mandatos de las autoridades ejecutivas en México tras la reforma constitucional de 2019. VII. Balance comparado y consideraciones finales.
\end{abstract}

\section{LA EXTENSIÓN DE LA REVOCACIÓN DEL MANDATO EN LAS DEMOCRACIAS LATINOAMERICANAS}

La revocación del mandato o recall, en expresión anglosajona, es un mecanismo de rendición de cuentas y control político que permite a los ciudadanos reaccionar frente a los representantes que han defraudado su confianza o incumplen su plan de gobierno impulsando la convocatoria de una consulta entre los electores que pueda conducir a la finalización anticipada del mandato y la sustitución de los mandatarios. La revocación del mandato se configura como un derecho complementario del derecho de los ciudadanos a elegir a sus autoridades, que se materializa mediante una nueva votación en la que estas pueden ser removidas 
de sus cargos antes del término de sus mandatos ${ }^{1}$. Al igual que las elecciones, la revocatoria, como se denomina en Latinoamérica, halla su fundamento en el principio de soberanía popular y se materializa mediante el voto, fuente de legitimidad de todo electo. Pero ello no implica que las elecciones y la revocación tengan la misma naturaleza. La elección es una técnica configurada para generar representación política; la revocación es la representación cuestionada. En la elección se otorga un mandato por un período de tiempo; en la revocación se pretende interrumpir ese mandato, dejándolo sin efecto.

La revocación del mandato ha sido, hasta hace unas décadas, un mecanismo de democracia directa poco extendido y apenas usado debido a las prevenciones que suscitaba su impacto sobre la representación política. En Europa, la regulación de la revocación se limitó a los cantones suizos de Berna, Schaffhausen, Solothurn, Ticino, Thurgau y Uri, donde se mantiene, y a los cantones de Argovia, Basilea-Campiña y Lucerna, donde se ha eliminado. Concebido como instrumento para interrumpir el mandato de las cámaras y de los gobiernos como colegio, y no para cesar a autoridades individuales, su utilización ha resultado excepcional, debido al uso de otros mecanismos de democracia directa y al buen funcionamiento de las garantías institucionales. Ningún otro territorio europeo adoptó la institución. Y sólo recientemente, las constituciones de varios Länder alemanes (Baden-Wurtemberg, Baviera, Berlín, Brandeburgo, Bremen y Renania-Palatinado) han incorporado un modelo similar al suizo de revocación colectiva bajo la forma de disolución anticipada de sus parlamentos producida a resultas de un referéndum revocatorio convocado a iniciativa popular ${ }^{2}$.

En el continente americano, la revocación del mandato en su vertiente individual cuenta con arraigo en EE.UU., donde no está regulada a nivel federal, pero sí en numerosos Estados federados y en un sesenta por ciento de las ciudades del país. La revocación fue introducida en la Carta de la ciudad de Los Ángeles en 1903 y, bajo el empuje del movimiento progresista, se extendió rápidamente a otros municipios y a los Estados de Oregón, California, Arizona, Nevada, Washington, New York, Kansas y Luisiana. En la actualidad, cuarenta y dos Estados de la Unión prevén la revocación a iniciativa popular de autoridades locales; dieciocho Estados y los distritos de Columbia, Guam y las Islas Vírgenes permiten la revocación de autoridades ejecutivas y legislativas estatales; doce Estados autorizan también la revocatoria de los jueces estatales y en cinco Estados sus constituciones regulan, incluso, la posible revocación de los senadores y los miembros de la Cámara de Representantes elegidos en el Estado respectivo, aunque, según los fiscales generales de estos Estados y el primer pronunciamiento judicial

1 Lijphart A., Democracies: Patterns of Majoritarian and Consensus Government in Twenty-One Countries, Yale University Press, New Haven, 1984, p. 200; Cronin, T. E., Direct Democracy. The Politics of Initiative, Referendum, and Recall, Harvard University Press, Cambridge, 1989, p. 145.

2 Rehmet, F. y Weber, T., Direkte Demokratie in den deutschen Bundesländern 1946 bis 2016. Volksbegehrensbericht 2017, Mehr Demokratie e.V., Berlín, 2016. 
recaído hasta la fecha - Committee to Recall Robert Menendez from the Office of U.S. Senator v. Wells, 7 A.3d720 (N.J. 2010)—, dicha revocación violaría la Constitución federal ${ }^{3}$. Durante décadas, el número de revocaciones activadas fue relativamente pequeño, pero a partir de los años sesenta del pasado siglo el uso de la institución se ha incrementado considerablemente. $\mathrm{E}$ incluso ha sido importada a la Columbia Británica mediante la Recall and Initiative Act 1991.

Siguiendo el modelo de recall individual, en Latinoamérica, la revocatoria del mandato fue introducida en la provincia argentina de Córdoba en 1923, a la que siguieron la provincia de Entre Ríos en 1933 y, años después, las provincias de Chaco y Neuquén en 1957, de Misiones en 1958 y de Corrientes en 1960. La revocatoria también fue regulada en el Estado mexicano de Yucatán en 1938. Y la República de Cuba la incorporó a su Constitución de 1940, aunque no llegó a regularse y desapareció de su entramado institucional hasta 1976, cuando el castrismo quiso recuperarla para los delegados a las asambleas municipales y de circunscripción, cayendo pronto en desuso.

El resto de países latinoamericanos ignoraron la revocatoria del mandato, e incluso las nuevas constituciones que apostaron por el fomento de la participación política, como la brasileña de 1988, omitieron su regulación. Durante décadas, en las democracias de América Latina predominó un modelo sustancialmente representativo donde el mandato no quedaba constreñido ni condicionado a la voluntad ciudadana más allá del período electoral ${ }^{4}$. Tras la tercera ola de democratizaciones, la revocación del mandato se introdujo, sin embargo, en algunas constituciones y legislaciones internas con el objetivo de contrarrestar la crisis de legitimidad de la representación política y abrir nuevos espacios institucionales para la participación y el control ciudadanos ${ }^{5}$. Y de ser una institución apenas conocida, la revocatoria se ha extendido en apenas tres décadas a varios de los países latinoamericanos más importantes, al punto de convertirse en una de las señas distintivas de la región.

En Argentina, tras la recuperación de las instituciones democráticas en 1983, las provincias de La Rioja (1986), Río Negro (1988), Santiago del Estero y Tierra de Fuego (ambas en 1991) y Chubut (1994) se sumaron a las provincias anteriormente citadas y previeron la revocatoria del mandato para las autoridades provinciales y locales. Colombia incorporó la revocatoria en la Constitución de 1991, junto con otros mecanismos de participación ciudadana, a fin de legitimar la imagen de un régimen político de los más estables de la región, pero excluyente. Su

3 Zimmerman, J. F., The Recall: Tribunal of the People, 2. ${ }^{a}$ ed., State University of New York Press, Albany, 2013, pp. 81-110; Noyes, H. S., The Law of Direct Democracy, Carolina Academic Press, Durham NC, 2014, pp. 35-40.

4 WelP, Y., «De venenos y fármacos. La regulación y prácticas de la revocatoria del mandato en Suiza y las Américas», en Y. WelP y U. SERdüLt (coords.), La dosis hace el veneno. Análisis de la revocatoria del mandato en América Latina, Estados Unidos y Suiza, CNE-ID, Quito, 2014, p. 252.

5 Eberhardt, M. ${ }^{a}$ L., «La revocatoria presidencial en América Latina. Ventajas y limitaciones. Los casos de Venezuela, Bolivia y Ecuador», Colombia Internacional, n. ${ }^{\circ}$ 92, 2017, p. 107. 
aplicación como derecho de participación quedó limitada, sin embargo, a los gobernadores y los alcaldes. Poco después la institución se introdujo en Perú, cuya Constitución de 1993 reguló la revocación del mandato para los alcaldes y regidores, las autoridades regionales y los magistrados de elección popular. En Panamá, el acto constitucional de 1983 incorporó una singular revocación de los diputados nacionales por decisión de los partidos que los postularon. Y tras la reforma constitucional de 2004, también se ha previsto la revocación de los diputados de libre postulación a iniciativa y por decisión de los electores y la revocación de autoridades locales.

En 1998, Ecuador introdujo la revocatoria para los alcaldes, prefectos y diputados. Diez años más tarde, el presidente Rafael Correa promovió la participación política directa en la Constitución de 2008, de suerte que la revocatoria se extendió a todas las autoridades electas, incluido el presidente de la República. En Venezuela, el deterioro económico y la crisis de los partidos tradicionales propiciaron el acceso al poder de Hugo Chávez, quien impulsó la aprobación de la Constitución de 1999 y la extensión de la revocatoria a todas las autoridades electas, incluida la Presidencia de la República. En Bolivia, la Ley N. ${ }^{\circ}$ 3850, de 12 de mayo de 2008, reguló ad hoc el referéndum revocatorio del presidente Evo Morales, de su vicepresidente y de ocho de los nueve prefectos departamentales. Meses después, la Constitución de 2009 extendió la revocatoria a todas las autoridades electas por voto popular. En los últimos años, también México se ha sumado a esta tendencia. En 1997, la revocación de mandatos fue regulada en Chihuahua; en 1998, en Zacatecas, y en 2011, en Oaxaca. Aguascalientes y Guerrero la incorporaron en 2014, Nuevo León y Jalisco en 2016, la Ciudad de México en 2018. Y en diciembre de 2019, ha entrado en vigor la reforma de la Constitución federal que, impulsada por López Obrador, reconoce el derecho a revocar los mandatos del presidente de la República, de los gobernadores de los Estados y del jefe de gobierno de la Ciudad de México.

En este trabajo se realiza un estudio comparado de las citadas regulaciones de revocación del mandato. Primeramente, analizamos la revocatoria de las autoridades regiones y locales en Colombia y Perú, cuyo diseño institucional y resultados difieren sensiblemente, para centrarnos a continuación en el régimen jurídico de la revocatoria en las entidades federativas y en los municipios de Argentina y México. En el siguiente epígrafe estudiamos las especialidades de la revocación del mandato en Panamá, donde los diputados nacionales y autoridades locales pueden ser cesados, dependiendo de su forma de postulación, por decisión de los partidos o por referéndum instado a iniciativa popular. Seguidamente, abordamos la revocatoria en Ecuador, Venezuela y Bolivia, donde la institución se ha extendido al presidente de la República en lo que vendría a ser equiparable al voto de censura al Ejecutivo propio del parlamentarismo, pero incoado y ejecutado por la ciudadanía. Y también se analiza la regulación de la revocatoria del presidente de la República en México tras la reforma constitucional de 2019. El trabajo concluye con un balance de los diseños institucionales y del rendimiento 
de la revocatoria en la región, en el que subrayamos la tensión existente entre las normas que regulan el procedimiento y sus condiciones efectivas de realización.

\section{LA REVOCACIÓN DEL MANDATO DE LAS AUTORIDADES REGIONALES Y LOCALES EN COLOMBIA Y PERÚ}

Colombia y Perú incorporaron la figura de la revocatoria del mandato casi simultáneamente y limitaron su aplicación a las autoridades regionales y locales. El desarrollo legislativo de la institución y su rendimiento han sido, sin embargo, muy distintos. En Colombia la revocatoria se ha caracterizado por sus elevados requisitos, su inoperancia y su escaso uso; en Perú, por su laxitud procedimental y generalizado empleo, incentivado por la previsión de elecciones anticipadas parciales cuando la revocación alcanzaba a más de un tercio de los miembros de las corporaciones.

Durante décadas, Colombia se distinguió por ser una de las democracias más estables de la región, pero a finales de los años ochenta del pasado siglo el sistema representativo quedó sumido en una grave crisis, de la que quiso salirse incorporando a la Constitución de 1991 formas complementarias de participación política, entre ellas la revocación del mandato, que se reconoció como un derecho de los ciudadanos a ejercer "en los casos y en la forma que estableciera la ley» (art. 40 de la Constitución). El desarrollo del instituto se produjo tres años después mediante la Ley 134 de 31 de mayo de 1994, sobre Mecanismos de Participación Ciudadana, cuyo artículo 6 limitó la revocatoria a los gobernadores de los departamentos y los alcaldes.

Para solicitar la revocación, la Ley exige que haya transcurrido más de un año de la toma de posesión del cargo y quede más de un año para la finalización del mandato. El primer límite temporal tiene por objeto otorgar al representante el tiempo necesario para ejercer el mandato, alcanzar resultados y poder ser valorado por ellos por los ciudadanos representados; el segundo se justifica en la conveniencia de neutralizar las pulsiones electoralistas tendentes a activar la revocatoria como medio de acortar los mandatos y adelantar las elecciones ${ }^{6}$. La solicitud de la revocatoria debe formalizarse por escrito sustentando las razones que la motivan, que pueden ser la insatisfacción general de la ciudadanía o el incumplimiento del programa de gobierno del mandatario. La insatisfacción general no resulta preciso fundamentarla, puesto que dicha causa depende de la confianza política de los electores. El caso de incumplimiento del programa está ligado, en cambio, al llamado «voto programático» (art. 259 de la Constitución), según el cual los ciudadanos que votan imponen como mandato al elegido el cumplimiento del programa de gobierno con el que concurrió a las elecciones, y su

6 García Campos, A., «La revocación del mandato: un breve acercamiento teórico», Quid Iuris, n. ${ }^{\circ}$ 1, Instituto de Investigaciones Jurídicas (UNAM), 2005, p. 28. 
incumplimiento puede justificar la revocación en la medida en que el legislador otorga a esas promesas una fuerza imperativa insólita en una democracia representativa ${ }^{7}$. Legitimando dicha causa, la Corte Constitucional de Colombia, en sentencia 11/1994, del 21 de enero, señaló que «el voto programático es una expresión de la soberanía popular y la democracia participativa que estrecha la relación entre los elegidos (alcaldes y gobernadores) y los ciudadanos electores. Y al consagrar que el elector impone al elegido por mandato un programa, el voto programático posibilita un control más efectivo de los primeros sobre estos últimos». El problema surge cuando el ejercicio de ese control queda supeditado al pronunciamiento del organismo electoral acerca de la existencia o no del incumplimiento, porque, de rechazar la revocatoria, el organismo «intermedia de una forma que puede generar conflictos y sospechas de parcialidad; y $[\ldots]$, de aprobarse la consulta avalando que hay incumplimiento, puede generar una extraña situación de solicitud de confirmación de un veredicto ya dado» ${ }^{8}$.

Conforme a la primera redacción del artículo 7 de la Ley 134/1994, la solicitud podía ser firmada únicamente por los ciudadanos que participaron en la jornada electoral que escogió al mandatario y en un número no inferior al cuarenta por ciento del total de los votos válidos emitidos. Adicionalmente, el derecho a votar en el referéndum revocatorio quedó limitado a los electores que hubieran participado en la elección de referencia, y la participación en la votación para que la revocación fuera efectiva debía ser, al menos, del sesenta por ciento de los votantes que sufragaron la elección a fin de garantizar una representatividad compatible entre ambos actos: el que designó al cargo público y el que lo destituye. Superados los requisitos previstos para la validez de la votación, el mandatario quedaba revocado si así lo decidía la mitad más uno de los ciudadanos que concurrieran a la revocatoria, en el caso de incumplimiento del programa, o el sesenta por ciento de los votos válidos en el caso de insatisfacción general. Revocada la autoridad, debía convocarse la elección del nuevo gobernador o alcalde en los dos meses siguientes a la destitución. Y, en el ínterin, ocuparía el cargo vacante en calidad de encargado por el presidente o por el gobernador del departamento un ciudadano propuesto por el propio grupo o partido político del mandatario revocado.

El umbral de participación requerido era excesivo en un país caracterizado por la baja participación electoral. Y resultaban particularmente onerosas las exigencias de que la solicitud fuera firmada sólo por los electores que hubieran

7 Como ha señalado M. ${ }^{a}$ L. EBERHARdT, esta causa de implementación de la revocación estaría sugiriendo «una especie de desplazamiento a [...] un tipo de mandato representativo modificado, o a un tipo de mandato representativo híbrido, donde los representantes quedan sujetos (bajo amenaza de ser revocados por incumplimiento o insatisfacción general) a las instrucciones que ellos mismos se han dado (el plan de gobierno postulado en campaña), y donde, aun así, dichos representantes representan a la nación en su conjunto y no a una parte o grupo dentro de ella». Cfr. «El mandato y su revocación desde la relación jurídico-política entre electores y elegidos», $R G D C$, n. ${ }^{\circ} 29,2019$, p. 8.

8 Welp, Y., «De venenos y fármacos. La regulación y prácticas de la revocatoria del mandato en Suiza y las Américas», op. cit., p. 254. 
participado en la elección del mandatario y que el derecho a voto en la revocatoria quedara limitado a dichos electores 9 . Debido a ello, el número de solicitudes de revocación presentadas en el periodo de 1994 a 2002 no pasó de 34; sólo 11 llegaron a la etapa de votación y ninguna logró la participación suficiente para revocar al mandatario. Con objeto de impulsar la institución, la Ley 741 de 31 de mayo de 2002 eliminó el requisito de que los firmantes de la solicitud debían haber participado en la elección del mandatario y redujo el umbral de participación para la validez del referéndum al cincuenta y cinco por ciento de los ciudadanos que votaron el día de la elección. Estos cambios propiciaron el incremento del número de solicitudes de revocación. Entre 2002 y 2012, se presentaron 95 iniciativas, de las cuales 26 lograron someterse a votación, aunque, de nuevo, ninguna prosperó al no alcanzar el quorum de participación exigido. Durante 2013 y 2014, el panorama no mejoró: pese a las solicitudes y a las revocatorias celebradas, ninguna autoridad fue revocada ${ }^{10}$. En no pocos casos, los votos a favor de las revocatorias superaron a los emitidos en contra, pero la baja participación invalidó las votaciones sin que la legitimidad de los mandatarios se viera reforzada.

Ante el escaso impacto de la reforma, la Ley 1757 de 6 de julio de 2015 ha reducido el porcentaje de firmas para solicitar el referéndum del cuarenta al treinta por ciento del total de votos que obtuvo el elegido y ha rebajado el quorum de participación del cincuenta y cinco al cuarenta por ciento de los ciudadanos que votaron el día en que se eligió al mandatario. A partir de esta nueva flexibilización, las revocatorias han aumentado y satisfecho los porcentajes, aunque el balance de la institución sigue siendo muy pobre debido, fundamentalmente, a la instrumentación de las revocatorias con fines electores y a la escasa participación ciudadana en las consultas convocadas ${ }^{11}$.

En Perú, el descrédito de los partidos políticos sirvió de justificación en 1992 al presidente Alberto Fujimori para disolver el Congreso e intervenir el resto de instituciones democráticas. Ante el rechazo internacional al «autogolpe»,

9 Véanse Matheus Brito, D., «La regulación del referendo revocatorio de mandato en Venezuela y en Colombia», Revista de Derecho Electoral, n. ${ }^{\circ}$ 6, 2008; Franco-Cuervo, A. B., "Colombia: instituciones, líderes políticos y abstención electoral (1991-2013)», en Y. WELP y U. SERDÜLT (coords.), La dosis hace el veneno. Análisis de la revocatoria del mandato en América Latina, Estados Unidos y Suiza, op. cit., p. 62.

10 En 2013 y 2014 se promovieron 60 revocatorias, de las cuales se votaron 14, pero ninguna prosperó. De entre todas las iniciativas, la más relevante fue la presentada contra el alcalde mayor de Bogotá, Gustavo Petro. Véase REY, J., «Entre la revocatoria y la destitución: Análisis del frustrado intento de revocar al alcalde de Bogota», Working Papers Series 48, Centre For Research on Direct Democracy, Zurich, 2015, pp. 10-15 y P. Robledo Silva, «Una mirada a la mediación de los partidos políticos en la revocatoria del mandato en Colombia: estudio del caso de Bogotá», en P. Biblino Campos (coord. ${ }^{a}$ ), Partidos políticos y mediaciones de la democracia directa, CEPC, Madrid, 2016, pp. 342-355.

11 Un balance en Eberhardt, M. ${ }^{a}$ L., «La revocatoria del mandato en Colombia: diseño institucional y resultados de su aplicación», Revista de Derecho Político, n. ${ }^{\circ}$ 103, 2018, pp. 469-476; Welp, Y. y MiLANESE, J. P., «Playing by the Rules of the Game: The Partisan Use of Recall Referendums in Colombia», Democratization, n. ${ }^{\circ}$ 25(8), 2018, pp. 1379-1396 y Erazo, L. C. y CHAmorro, L., «Democratizando la revocatoria para alcaldes en Ecuador y Colombia: la gobernanza local en la encrucijada», Íconos. Revista de Ciencias Sociales, n. ${ }^{\circ}$ 6, 2019, pp. 83-86. 
Fujimori se comprometió a convocar un Congreso Constituyente encargado de restablecer el equilibrio de poderes y garantizar la participación política. La Constitución resultante, ratificada en referéndum en agosto de 1993, reguló diversos mecanismos participativos, entre ellos la revocatoria del mandato para los alcaldes y regidores (art. 191), las autoridades regionales (art. 198) y los magistrados de elección popular (art. 139.17). Y la Ley 26.300 de 2 de mayo de 1994, sobre los derechos de participación y control ciudadanos, facilitó su ejercicio al punto de hacer del Perú el país con más revocatorias activadas del mundo. Debido a su excesivo uso y al ingente número de autoridades revocadas, dicha regulación fue modificada parcialmente por Ley 29.313 de 6 de enero de 2009 y, en profundidad, por la Ley 30.315 de 13 de marzo de 2015.

La Ley 26.300 de 1994 excluyo la revocatoria durante el primero y el último año del mandato, salvo en el caso de los jueces de paz. A partir de ahí, la regulación fue laxa. La solicitud de la revocación debía de estar fundamentada, pero servía a tal efecto cualquier causa puesto que no necesitaba ser probada. La iniciativa debía estar avalada por más del veinticinco por ciento de los electores que votaron a la autoridad en cuestión, pero también se admitía con cuatrocientas mil firmas presentadas ante la oficina de procesos electorales; un umbral muy bajo que, en la ciudad de Lima, sólo representaba el $6,7 \%$ de los electores, lo que hacía a sus cargos muy vulnerables. A diferencia de otros países, no se preveía un límite temporal para conseguir las firmas de adhesión, por lo que, de no lograrse el primer año, se seguían solicitando y acumulando para el segundo año del período del mandato en que la revocatoria es posible. E incluso antes de que la Ley 29.313 de 2009 lo prohibiera, la revocatoria podía solicitarse más de una vez durante el mandato de la autoridad electa.

El artículo 23 de la Ley 26.300 requería para revocar al mandatario el voto favorable de la mitad más uno de los electores, pero, aunque la referencia para dicho cómputo debía ser el padrón electoral, el organismo electoral interpretó que el cómputo debía hacerse sobre los votos válidos. La Ley 29.313 de 6 de enero de 2009 ratificó dicha opción, que facilitaba mucho la revocación, pero condicionó la validez de la votación a la participación del cincuenta por ciento de los empadronados. Si la revocatoria afectaba a una única autoridad, el artículo 24 de la Ley 26300 preveía su sustitución automática. Al presidente regional, le sustituía el vicepresidente; al vicepresidente, el consejero designado por el Consejo regional; al consejero regional, su respectivo accesitario; al alcalde, el primer regidor que le seguía en la lista electoral; y al regidor, el suplente de su lista. Pero de ser revocados más de un tercio de los miembros del Consejo Regional o del Concejo Municipal, debían convocarse nuevas elecciones para seleccionar a sus sustitutos hasta concluir el período del mandato. Se forzaba, así, la celebración de unas elecciones anticipadas parciales en las que el partido en el gobierno podía perder la mayoría en la corporación sin que el ganador la lograra.

Debido a las facilidades de la regulación y a una dinámica interpartidista proclive a su utilización, desde 1997 hasta 2013 se realizó un uso intensivo de la revocatoria, habiéndose celebrado más de cinco mil consultas que afectaron a once 
provincias, incluida la capital, y a más de mil distritos o municipios, en los que fueron revocados trescientos tres alcaldes y mil cuatrocientos treinta y seis regidores ${ }^{12}$. Desde el punto de vista participativo, ello representaba un éxito, pero el balance no era positivo atendiendo a los efectos que generó la secuencia entre las revocatorias y las elecciones anticipadas. El primer efecto fue que la expectativa de anticipar las elecciones se convirtió en un incentivo de la revocatoria por parte de los candidatos que no alcanzaron el poder local; el segundo fue la provisionalidad en la acción de gobierno, puesto que, entre la revocación de más de un tercio del órgano y la elección subsiguiente, quienes ocupaban los cargos de los cesados eran sus accesitarios y suplentes; el tercero fue la ingobernabilidad en que las instituciones se sumían si, tras las revocatorias y las elecciones parciales, el presidente regional o el alcalde perdía su mayoría de gobierno, como paso en 2013 tras las revocatorias contra la alcaldesa de Lima, Susana Villarán, y los miembros del Concejo, en las que la alcaldesa no fue revocada, pero sí lo fueron más de dos tercios de los regidores, lo que dio lugar a nuevas elecciones en las que Villarán perdió su mayoría de gobierno ${ }^{13}$.

Los problemas de gobernabilidad provocados por el uso excesivo y desviado de la revocatoria motivaron la reforma de la institución llevada a cabo en la Ley 30.135 de 13 de marzo de 2015, que limitó las iniciativas de revocatoria a una solicitud por autoridad local y por período, estableció plazos únicos para la presentación de solicitudes (junio del segundo año de mandato) y para la votación (junio del tercer año de mandato) y eliminó la posibilidad de instarla con 400.000 firmas y las elecciones parciales anticipadas como mecanismo de reemplazo de las autorizadas revocadas. Ello redujo significativamente el número de solicitudes y de mandatarios revocados en las consultas de junio de 2017: 13 alcaldes y 41 regidores cesados de 89 consultas celebradas, cifras siete veces menores que las registradas en 2013 y casi quince veces menores que las de 2012, lo que, a juicio de la doctrina, ha permitido recuperar las genuinas funciones de accountability y control vertical de la revocatoria ${ }^{14}$.

\section{LA REVOCACIÓN DEL MANDATO EN LOS ENTES FEDERADOS Y LOS MUNICIPIOS DE ARGENTINA Y MÉXICO}

En Argentina y México la revocación del mandato de las autoridades estatales y locales está regulada en las constituciones de las entidades federadas y, en el

12 Véase la web del Jurado Nacional de Elecciones: https://infogob.jne.gob.pe/Eleccion.

13 Tuesta Soldevilla, F., «Perú: entre la participación y la gobernabilidad local (1997-2013)», en Y. Welp y U. Serdült (coords.), La dosis hace el veneno. Análisis de la revocatoria del mandato..., op. cit., pp. 16-17; VÁsquez Oruna, E. M., «Las pretensiones revocadoras: el caso de Lima», en F. Tuesta Soldevilla (ed.), Una onda expansiva: las revocatorias en el Perú y América Latina, Jurado Nacional de Elecciones, Lima, 2014, pp. 67-92.

14 Eberhardt, M. ${ }^{a}$ L., «La revocatoria del mandato en Perú: diseño institucional y resultados de su aplicación», Revista Derecho del Estado, n. ${ }^{\circ} 43,2019$, pp. 335-340. 
caso de las autoridades locales argentinas, también en las leyes de municipalidades y las cartas orgánicas municipales. En las provincias argentinas de Córdoba y Entre Ríos la revocatoria se introdujo en 1923 y 1933, respectivamente. Y en el Estado mexicano de Yucatán, en 1938. Pese a tan temprano reconocimiento, extendido más tarde a otras provincias y otros estados, su utilización ha sido escasa y se ha visto condicionada por varios pronunciamientos judiciales adversos dictados a instancias de las autoridades cuestionadas.

En Argentina, la revocatoria de mandatos de las autoridades a nivel provincial está prevista en las provincias de Chaco, Chubut, Córdoba, Corrientes, La Rioja, Santiago del Estero y Tierra del Fuego. También en la Ciudad Autónoma de Buenos Aires. Y la revocatoria a nivel municipal está regulada, además de en las anteriores, en las provincias de San Luis, San Juan, Río Negro, Neuquén, Misiones, Entre Ríos y Catamarca, aunque la constitución provincial de esta última no menciona la revocatoria, que ha sido regulada directamente en las respectivas cartas orgánicas municipales ${ }^{15}$.

Las regulaciones constitucionales de las revocatorias de mandato a nivel provincial son muy similares. Las solicitudes deben ir firmadas por un veinte por ciento de los electores, menos en Chaco, donde se exige sólo un diez por ciento. Las causas para revocar son «las atinentes al desempeño de las funciones»o «el mal desempeño de las funciones», salvo en Chubut y Tierra de Fuego, en las que no es preciso alegar causa alguna, y de nuevo en Chaco, donde se establece que las posibles causas son «las previstas para el juicio político», esto es, la incapacidad física o mental sobreviniente, el mal desempeño o falta de cumplimiento de los deberes del cargo o la comisión de delito en el ejercicio de sus funciones. En Buenos Aires, Corrientes, Chaco y Santiago del Estero la revocatoria no puede plantearse antes del primer año de ejercicio del mandato, ni en los últimos seis meses del mismo. En Tierra de Fuego no puede solicitarse durante la primera mitad del mandato. Las constituciones de Chubut y La Rioja, en cambio, no mencionan plazos. Para revocar a las autoridades electas, las provincias de Corrientes, Chaco, La Rioja y la Ciudad de Buenos Aires exigen que los votos a favor de la revocatoria superen el cincuenta por ciento de los inscritos en el padrón electoral. Chubut y Santiago del Estero exigen sólo la mayoría simple de los votos válidamente emitidos en la consulta, aunque esta última requiere para tener validez que la participación electoral haya superado la mitad de los inscritos en el padrón electoral ${ }^{16}$.

De las veinte provincias que otorgan autonomía institucional a sus municipios, catorce reconocen en sus constituciones la revocatoria del mandato a nivel municipal. En un primer grupo, integrado por las provincias de Chaco, Chubut,

15 Arques, F., «Argentina: una herramienta de los gobernados en manos de los gobernantes», en Y. WELP y U. SERDÜLT (coords.), La dosis hace el veneno..., op. cit., p. 160.

16 Un estudio comparado de las regulaciones constitucionales provinciales en EBERHARDT, M. ${ }^{a}$ L., «La revocatoria de mandato a nivel subnacional en Argentina: normativa y casos», Cuestiones constitucionales. Revista Mexicana de Derecho Constitucional, n. ${ }^{\circ}$. 42, 2020, pp. 185-196. 
Córdoba, Corrientes, Neuquén, Río Negro y San Juan, esa revocatoria de las autoridades locales está regulada en las cartas orgánicas de los municipios y existe, además, la regulación contenida en la ley orgánica de municipalidades de cada provincia, que rige para los municipios de menor jerarquía que no poseen carta orgánica. En un segundo grupo, al que pertenecen Catamarca, Jujuy, Misiones, San Luis, Santiago del Estero y Tierra de Fuego, no existe ley orgánica de municipalidades de ámbito provincial, por lo que la revocatoria prevista en sus constituciones está regulada en las cartas orgánicas municipales y sólo en los municipios con dicha carta puede activarse. La Rioja queda al margen de ambos grupos, puesto que en esta provincia no existen cartas orgánicas y la revocatoria sólo se regula en su ley orgánica municipal.

En las leyes orgánicas de municipalidades de las provincias citadas, los porcentajes de firmas requeridos para solicitar la revocatoria oscila entre el diez y el veinte por ciento de los inscritos en el padrón correspondiente, el período para reunirlas es de treinta días, las causas de revocación más comunes son las referidas al mal desempeño de las funciones del cargo y la mayoría exigida para revocar se computa sobre los votos válidos emitidos. Las cartas orgánicas municipales contienen una regulación similar a las leyes orgánicas de municipalidades, aunque algunas ciudades han incorporado ciertas singularidades. La ciudad de La Banda exige para activar la revocatoria un treinta por ciento de avales y Perico un treinta y cinco por ciento. Santiago del Estero y San Fernando del Valle de Catamarca demandan un umbral de participación del cincuenta por ciento y del cincuenta y uno por ciento, respectivamente. Y, apartándose del resto, Villa Mercedes exige para mantener en el cargo a la autoridad cuestionada que en la revocatoria se igualen, al menos, los votos con los que fue electa o se supere el cincuenta por ciento de votos a favor ${ }^{17}$.

Pese a estar prevista en los niveles de gobierno provincial y municipal, la experiencia práctica de la revocatoria es muy limitada en Argentina. A nivel provincial, sólo Chaco y la Ciudad Autónoma de Buenos Aires han sancionado las leyes reguladoras necesarias para hacer uso de la institución. Los requisitos exigidos son, además, muy elevados, particularmente el porcentaje de firmas y la exigencia para revocar de una mayoría superior al cincuenta por ciento de los electores inscritos, en un país donde la participación electoral no supera el setenta y cinco por ciento. En estas condiciones, las posibilidades de que una revocatoria prospere son remotas, como evidenció el proceso de revocación promovido en la Ciudad de Buenos Aires por el propio jefe de gobierno, Aníbal Ibarra, que terminó impulsando el propio Ibarra a fin de intentar desactivar el juicio político incoado por la legislatura y reforzar su legitimidad ${ }^{18}$.

17 Arques, F., «La revocatoria del mandato a nivel subnacional en Argentina», en F. Tuesta Soldevilla (ed.), Una onda expansiva: las revocatorias en el Perú y América Latina, op. cit., pp. 165-169.

18 Pese a impulsar la revocatoria el propio mandatario, la iniciativa fracasó. Como reconoció el propio Ibarra, la revocatoria «es un sistema regulado para que no se aplique. Si uno toma en cuenta la cantidad de 
En el ámbito municipal el balance es más alentador debido a las dimensiones reducidas de los distritos, los menores requisitos de la revocatoria y el elevado número de municipios que regulan la institución en su carta orgánica. El problema ha sido, sin embargo, la judicialización que las revocatorias han padecido a resultas de sendos recursos de los intendentes afectados y que se han saldado de modo desigual. En las revocatorias incoadas en las localidades de Deán Funes y Villa Ascasubi, ambas en 2011, los tribunales de justicia decidieron proseguir con el procedimiento. En las revocatorias de la ciudad de Córdoba, en 2002, y de la localidad de Famatina, en 2012, los recursos judiciales suspendieron, en cambio, los procedimientos. En el primer caso, porque estaba en trámite un juicio político y la Suprema Corte consideró la revocatoria incompatible; en el segundo, porque el Tribunal Electoral Provincial declaró inconstitucionales varios preceptos de la ley reguladora aduciendo la imposibilidad de defensa de los recurrentes. Lejos de considerar la revocatoria como un derecho político cuyo ejercicio se fundamenta en una causa que no precisa ser probada, el Tribunal estimó que no exigir prueba impide valorar judicialmente su concurrencia y garantizar debidamente el derecho de defensa. Dicha tesis, como es obvio, altera la naturaleza política de la revocación al pretender revisar su fundamento, anima a toda autoridad a recurrir y, de generalizarse, puede arrumbar cualquier intento de implementación de la revocatoria en el país ${ }^{19}$.

Algo similar ha ocurrido en los últimos años con la revocatoria prevista en varios Estados mexicanos. Hasta 2012, sólo Yucatán, Chihuahua, Zacatecas y Oaxaca regulaban la institución. El artículo 30 XLI de la Constitución de Yucatán reconocía la revocación del mandato del gobernador y de los diputados como una atribución del Congreso del Estado, que podía ser ejercida cuando lo solicitara el sesenta y cinco por ciento de los electores y se obtuviera el voto unánime de la Legislatura, en el caso del gobernador, y de sus dos terceras partes, en el caso de los diputados. El artículo 27 de la Constitución de Chihuahua, reformada en 1997, permitía la revocación del gobernador, los diputados, los presidentes municipales, los regidores y los síndicos a iniciativa popular. La institución fue desarrollada por ley el 18 de octubre de 1997 y se conservó en la Ley Electoral de 2009. Los artículos 14 y 15 de la Constitución de Zacatecas reconocen la participación en los procesos de revocación de mandatos como un derecho de los ciudadanos. Y lo mismo hacen los artículos 23, 24 y 25 de la Constitución de Oaxaca, desarrollados por la Ley de 17 de agosto de 2012, de Participación Ciudadana, en su capítulo cuarto, aplicable a la revocación del gobernador ${ }^{20}$.

firmas que se tienen que juntar, más la cantidad de votos que hay que sacar para legalmente revocar el mandato de alguien, es imposible». Cit. por EBerhardt, M. ${ }^{a}$ L., "La revocatoria de mandato a nivel subnacional en Argentina: normativa y casos», op. cit., p. 200.

19 Arques, F., «La revocatoria del mandato a nivel subnacional en Argentina», op. cit., pp. 169-172.

20 Gamboa Montejano, C. y Ayala Cordero, A., Revocación de mandato. Estudio comparativo a nivel local e internacional, y de iniciativas presentadas en el tema, Cámara de Diputados, México, 2016, pp. 10-35. 
En septiembre de 2009, varios integrantes del Congreso de Chihuahua, el Partido del Trabajo y el Procurador General de la República ejercieron sendas acciones de inconstitucionalidad contra la regulación de la revocatoria de Chihuahua. Y lo mismo hizo el Procurador General de la República contra el artículo 30, fracción XLI, de la Constitución de Yucatán. A resultas de dichas acciones, la Suprema Corte de Justicia de la Nación dictó las tesis jurisprudenciales P./J. 10a. 21/2012, para el caso de Yucatán, y P./J. 9a. 28/2013, sobre Chihuahua, en las que declaró inconstitucionales ambas regulaciones. «La Constitución General de la República — subrayó la Suprema Corte- sólo prevé la responsabilidad civil, penal, administrativa y la política de las autoridades, pero no contempla la figura de la revocación de mandato popular [...], lo que implica que las disposiciones combatidas establecen un nuevo sistema de responsabilidad que no tiene sustento constitucional» (P./J. 9a. 28/2013, considerando décimo octavo $)^{21}$.

La declaración de invalidez de estos preceptos y la posibilidad de que la Procuraduría u otros actores impugnaran en cualquier momento otras regulaciones estatales no disuadió, sin embargo, a otros Estados a la hora de incorporar la revocatoria a su régimen jurídico. En 2013, Morelos reguló la revocación del mandato en el artículo 19 bis, apartado A, fracción IV, de su Constitución y las desarrolló en la Ley de 5 de marzo de 2014, de Participación Ciudadana del Estado, más tarde derogada. El Estado de Guerrero la reguló en 2014 en los artículos 19 y 128, fracción IX, de su Constitución local. Aguascalientes la incorporó en 2014 en el artículo 17 de su Constitución, encomendando al legislador la regulación de sus causas y procedimientos. Nuevo León constitucionalizó la revocatoria en 2016 y la ha reglamentado en el Libro Tercero, Capítulo Sexto, de la Ley de Participación Ciudadana para el Estado. En la reforma de su Constitución llevada a cabo en 2016, Jalisco ha previsto la revocación del gobernador y de los diputados, presidentes municipales, regidores y síndico a solicitud del cinco por ciento del listado nominal (art. 11.VIII). Chihuahua ha recuperado la revocatoria popular en la Ley de 26 de abril de 2018, de Participación Ciudadana, cuyos artículos 53 a 60 la hacen extensiva a quienes ostenten la titularidad del Poder Ejecutivo del Estado, las diputaciones locales, las presidencias municipales y las sindicaturas. Y la ciudad de México la ha incorporado en el artículo 25 de su Constitución en septiembre de 2018, a solicitud de un mínimo del diez por ciento de las personas inscritas en la lista nominal de electores del ámbito respectivo, con un umbral de participación del cuarenta por ciento y una mayoría a favor del sesenta por ciento de los votos válidos.

21 Las sentencias correspondientes a la acción de inconstitucionalidad 63/2009 y sus acumuladas y a la acción de inconstitucionalidad 8/2010 pueden verse en http://www.dof.gob.mx. Un análisis de ambas, en Limón Magaña, W., «Implementación de la revocación del mandato en México y legitimidad democrática», Justicia Electoral, n. ${ }^{\circ}$ 20, 2017, pp. 109-115. 
Esta apuesta por la generalización de la revocación no podía ocultar, sin embargo, su precariedad, puesto que, a tenor de la citada doctrina de la Suprema Corte, cualquier acción de inconstitucionalidad, juicio de amparo o juicio de protección de derechos político-electorales interpuesto por los afectados podía dar al traste con las regulaciones estatales y paralizar su puesta en práctica. De ahí la ausencia de revocatorias durante estos años y la utilización en su defecto del juicio político ${ }^{22}$. La situación, no obstante, ha cambiado drásticamente tras la aprobación de la reforma constitucional en materia de consulta popular y revocación del mandato impulsada por el nuevo presidente de la República, Andrés Manuel López Obrador. Aprobada por ambas Cámaras del Congreso de la Unión en otoño de 2019 y ratificada por la mayoría de las legislaturas estatales, la Constitución federal ha previsto la revocatoria para el presidente de la República, los gobernadores de los Estados y el jefe del gobierno de la Ciudad de México. Según la transitoria sexta, las entidades federativas que reconocieron la institución con anterioridad a la reforma deben adaptarla a las previsiones constitucionales. Y en el plazo de dieciocho meses a contar desde la entrada en vigor de la reforma, todas las constituciones de las entidades federativas deberán garantizar el derecho ciudadano a solicitar la revocación del mandato de los titulares del Poder Ejecutivo. Tras la entrada en vigor de este mandato constitucional, el proceso de generalización de la revocatoria ya ha comenzado y, a su término, todos los Estados mexicanos dispondrán de revocatoria del mandato. Tras su implementación, cabrá valorar su rendimiento.

\section{LA REVOCACIÓN EN PANAMÁ POR DECISIÓN DE LOS PARTIDOS POLÍTICOS Y POR REFERÉNDUM A INICIATIVA POPULAR}

En Panamá, la cúpula militar que tutelaba el régimen político tras el fallecimiento del general Omar Torrijos decidió democratizar la Constitución de 1972 mediante una profunda reforma materializada en el Acto Constitucional de 1983, en cuyo artículo 146 se introdujo una singular modalidad de revocación del mandato de los legisladores a cargo de los partidos políticos que los hubieran postulado, no de los electores de su circunscripción ${ }^{23}$. Se constitucionalizó de este modo una suerte de mandato imperativo de partido que venía a condicionar el

22 Corzo Sosa, E., «Partidos políticos e instituciones de democracia participativa en México: especial referencia a la revocación del mandato y a la iniciativa ciudadana», P. Biblino Campos (coord. ${ }^{2}$ ), Partidos políticos y mediaciones de la democracia directa, op. cit., pp. 376-382.

23 La Constitución de 1972 introdujo la revocatoria entre las causas de pérdida del mandato de los representantes del corregimiento (miembros de los consejos municipales), pero la Ley $n .{ }^{\circ} 19$ de 9 de julio de 1980 impidió en la práctica su implementación al exigir que la solicitud fuera avalada por el setenta y cinco por ciento de los empadronados y votara a favor de la revocación idéntico porcentaje del censo. 
mandato representativo libre, en la medida en que sobre los representantes pendía la amenaza de revocación en los supuestos de abandono de la militancia partidista, de violación grave de los estatutos de sus partidos o de actuación contraria a su plataforma ideológica, política o programática ${ }^{24}$.

Tras la reforma de 2004, el artículo 151 de la Constitución confirmó la revocación del mandato de los diputados a iniciativa y por decisión de los partidos. Adicionalmente, se ha legitimado a los electores del circuito para solicitar al Tribunal Electoral la apertura de un procedimiento de revocación de los diputados de libre postulación, ajenos a partidos, que hubieran elegido en dicho circuito, cumpliendo los requisitos y las formalidades que la ley establezca. Otorgando carta de naturaleza a esta relación fiduciaria, el constituyente subrayó que, si bien ambos tipos de diputados actúan en interés de la Nación, no la representan, sino que «representan en la Asamblea Nacional a sus respectivos partidos políticos y a los electores de su circuito electoral»(art. 150 de la Constitución). Ambas modalidades de revocación, a instancias de los partidos o de los electores según el tipo de postulación, fueron también extendidas a los representantes del corregimiento (art. 227 de la Constitución). La ley 60 de 29 de diciembre 2006, de reforma del Código Electoral, desarrolló dichas previsiones constitucionales en su artículo 328, letras A a L, e incorporó la posibilidad de que los representantes de los corregimientos postulados por los partidos sean revocados por decisión de los electores —no sólo de sus partidos- mediante un referéndum convocado al efecto en los términos que se indican para la revocación de los representantes de libre postulación. En la actualidad, tras diversas reformas, la revocación de mandatos de los diputados y de los representantes de los corregimientos se regula en los artículos 438 a 453 del Código Electoral. Y ampliando el ámbito de la revocación partidista, también se ha reconocido la posibilidad de revocar a los alcaldes de distrito postulados por los partidos políticos en la forma prevista para los representantes de los corregimientos.

Los motivos o causas aducidos para la revocación del mandato de los diputados y los representantes de los corregimientos por los propios partidos deben establecerse en los estatutos de los partidos y haber sido aprobadas mediante resolución dictada por el Tribunal Electoral con anterioridad a la fecha de postulación. Al diputado o representante afectado debe reconocérsele el derecho, dentro del partido, a ser oído y a defenderse en dos instancias. Previo al inicio del proceso intrapartidista, los partidos políticos pueden implementar mecanismos de consulta popular entre los electores del circuito electoral correspondiente, regulándolos en

24 La revocatoria partidaria es, como ha señalado M. ${ }^{a}$ L. EBERHARDT, «un mecanismo de control y sanción intra-partidaria que fomenta la disciplina de los diputados y demás representantes para que se mantengan en línea con y bajo las órdenes de los líderes del partido por el cual fueron elegidos. Asimismo, pretende desalentar las rupturas de bloque y el traspaso a otra agrupación política una vez asumido el cargo». Cfr. «Revocatoria popular y revocatoria partidaria en Panamá: diseño institucional y casos de aplicación», Revista de Investigações Constitucionais, vol. 7, n. ${ }^{\circ}$. 2, 2020, p. 404. 
sus estatutos. Agotadas las instancias y los procedimientos internos del partido, el afectado por la revocatoria puede impugnar la decisión ante el Tribunal Electoral, dentro de los diez días hábiles siguientes, con efectos suspensivos de la decisión del partido.

La segunda modalidad de revocación, aplicable a los diputados nacionales y representantes de los corregimientos electos por libre postulación, se incoa a iniciativa ciudadana mediante referéndum convocado en el circuito electoral correspondiente. En estos casos, la revocación no puede plantearse durante el primer año de mandato y tampoco durante el último. La solicitud debe partir de un número de electores no menor a un treinta por ciento de los que conformaban el padrón del circuito en el momento de la elección del diputado. Y, celebrado el referéndum, el mandato del diputado nacional de libre postulación queda revocado si la mayoría de los votos válidos resultan afirmativos siempre que participe en la votación un mínimo del cincuenta por ciento de los inscritos en el padrón electoral. En el caso de los representantes del corregimiento, la revocación se produce si la mayoría de votos son afirmativos, sin necesidad de superar el referido umbral de participación. Y lo mismo se prevé para los alcaldes de libre postulación, cuya revocación sólo precisa mayoría de votos afirmativos ${ }^{25}$.

El balance de ambas modalidades de revocación es muy limitado. Hasta 1995 no se produjo la primera revocación por decisión partidista, que afectó a un diputado del Partido Revolucionario Democrático. A dicha revocación le siguieron varias iniciativas más, pero no prosperaron. De 2010 a 2014 la revocación fue impracticable por las exorbitantes exigencias que introdujo el legislador en la reforma del Código Electoral de abril de 2010, que blindó a los tránsfugas frente a sus partidos ${ }^{26}$. La posterior reforma de 2013 derogó dichas exigencias, lo que posibilitó la activación de varios procedimientos revocatorios. El más conocido fue impulsado en 2016 por el partido Cambio Democrático contra varios diputados que incumplieron sus directrices de voto, pero el procedimiento no concluyó con su destitución. La revocación de cargos de libre postulación por los propios electores no ha corrido mejor suerte. Desde su regulación, ningún representante de libre postulación ha sido revocado a iniciativa popular debido al reducido

25 Un análisis del régimen jurídico de ambas modalidades de revocatoria en Eberhardt, M.. ${ }^{a}$., op. cit., pp. 408-414.

26 La ley 14 de1 3 de abril de 2010, de reforma del Código Electoral, extremó las exigencias para revocar el mandato de los electos por los partidos al requerir, para dar cumplimiento a la garantía de la doble instancia, una primera decisión unánime del Directorio Nacional y una segunda decisión del Congreso o Convención Nacional, adoptada por dos tercios, y exigiendo adicionalmente para su perfección que fuera sometida a consulta y aprobada por el voto favorable de las dos terceras partes de los electores del circuito electoral. Por excesivas, estas trabas en la aplicación de la revocatoria duraron poco. El transfuguismo de varias decenas de diputados, que se vieron libres de la amenaza de revocación, condujo al presidente, Ricardo Martinelli, a eliminar dichas exigencias y a flexibilizar los requisitos mediante la Ley 4 de 7 de febrero de 2013, de reforma del Código Electoral. Véase Jiménez Badillo, M., «Transfuguismo legislativo en Guatemala y Panamá», Anuario CIEP, n. ${ }^{\circ}$ 6, Universidad de Costa Rica, San José, 2015, pp. 24-30. 
número de diputados, representantes o alcaldes de libre postulación y, sobre todo, al elevado porcentaje de firmas que requiere la incoación del referéndum.

\section{LA REVOCACIÓN DEL MANDATO DE TODOS LOS CARGOS DE ELECCIÓN POPULAR EN ECUADOR, VENEZUELA Y BOLIVIA: EN ESPECIAL, LA REVOCACIÓN PRESIDENCIAL}

Ecuador, Venezuela y Bolivia han optado por extender la revocación del mandato a todos los cargos y magistraturas de elección popular, incluido el cargo de presidente de la República. Las regulaciones constitucionales de la institución son, en los tres casos, generosas, pero los requisitos y restricciones establecidos en la normativa que las desarrolla dificultan extraordinariamente su ejercicio.

En Ecuador, la incorporación y posterior extensión de la revocatoria se produjo en un contexto de inestabilidad institucional en el que confluyó la crisis de legitimidad del sistema de partidos y la presión de nuevos movimientos sociales para ampliar los espacios de participación. En 1997, tras semanas de protestas, el presidente Abdalá Bucaram fue destituido por el Congreso Nacional acusado de incapacidad mental. El cargo vacante fue ocupado por el presidente del Congreso, Alarcón Rivera, quien convocó un referéndum para legitimar la destitución de su predecesor e impulsar una Asamblea constituyente. Entre otras cuestiones referidas a la configuración del Estado, en dicho referéndum se preguntó sobre la institucionalización de la revocatoria: «¿Está usted de acuerdo — rezaba la pregunta 13- con que la Constitución Política contemple el principio de la revocatoria del mandato de quienes, habiendo sido elegidos por el voto popular, incumplan con las normas morales, legales y de eficiencia atinentes al ejercicio de sus funciones?». El sesenta por ciento de los votantes respondió afirmativamente. Y, dando cumplimiento parcial ese pronunciamiento, la Constitución de 1998 introdujo la revocación del mandato para los alcaldes, prefectos y diputados de elección popular por actos de corrupción o incumplimiento injustificado de su plan de trabajo (art. 109). La regulación en detalle de la revocatoria se produjo en la Ley Orgánica de Elecciones de 5 de julio de 2000 y, especialmente, en el Reglamento para consulta popular y revocatoria del mandato de 29 de junio de 2001.

Constitucionalmente, la revocatoria se configuró como un derecho político: en casos de corrupción podía ejercerse en cualquier momento, y en caso de incumplimiento del plan de trabajo, después de haber trascurrido el primer año y antes del último del mandato sin otras limitaciones ni requisitos constitucionales. El Reglamento de 2001 introdujo, sin embargo, exigencias adicionales que constriñeron el ejercicio del referido derecho, hasta desnaturalizarlo. En la revocación por actos de corrupción añadió la necesidad de una sentencia ejecutoria previa que determinase la responsabilidad de la autoridad en dichos actos, lo que desactivaba la revocación por esta causa porque, de existir sentencia previa, la autoridad quedaba inhabilitada y la 
revocatoria perdía su objeto ${ }^{27}$. Configurado como derecho, la revocación por incumplimiento del plan de trabajo sólo podía depender del mantenimiento o no de la confianza de los electores. El Reglamento incorporó, sin embargo, la necesidad de justificar dicho incumplimiento y atribuyó al Tribunal Supremo Electoral la facultad de verificarlo para poder iniciar el proceso revocatorio. Según el artículo 110 de la Constitución, la solicitud de la revocación debía ir avalada por al menos un treinta por ciento de los inscritos en el correspondiente padrón, pero, adicionalmente, el Reglamento exigió que los firmantes hubiesen participado en la elección de la autoridad a revocar. Superado el umbral, la comisión jurídica del Tribunal Supremo Electoral debía notificar a la autoridad cuestionada para que alegara en su defensa y someter el caso a estudio. Tras su informe, el Tribunal Electoral de cada provincia podía aceptar o rechazar la solicitud e incluso en ciertos casos, ante revocatorias carentes de fundamento, podía activar un insólito proceso penal contra los promotores de la iniciativa (art. 51 del Reglamento).

Con tan restrictiva regulación, la revocatoria se mantuvo inactiva durante más de una década y su función de contrapeso fue suplida por la acción popular directa en los ámbitos subcentrales, pero también a nivel nacional, donde dos presidentes más fueron derrocados tras intensas protestas. En 2000, fue destituido por abandono del cargo Jamil Mahuad Witt y en 2005 le tocó el turno al presidente Lucio Gutiérrez, desbordado por la violencia en las calles de Quito. En este contexto de destituciones de facto, la extensión de la revocatoria a la más alta magistratura del país fue vista por muchos como una necesidad política; y el impulso efectivo de la institución, como una urgencia.

La victoria de Rafael Correa en las elecciones presidenciales de 2006 abrió un nuevo proceso constituyente que concluyó con la Constitución de 2008, cuyo artículo 61.6 reconoció el derecho de los ecuatorianos a revocar el mandato conferido a todas las autoridades de elección popular, incluido el presidente de la República, y cuyos artículos 105 a 107, desarrollados por la Ley Orgánica 175/2010, de 20 abril, de Participación Ciudadana, flexibilizaron las condiciones para su activación. El umbral de firmas requerido se redujo del treinta al quince por ciento de los inscritos en el padrón electoral, en caso del presidente, y al diez por ciento para el resto de las autoridades. El plazo para reunirlas fue ampliado a 180 días. La exigencia de justificación del incumplimiento del plan de trabajo fue eliminada. Y la mayoría absoluta necesaria para revocar a las autoridades pasó a computarse sobre los votos válidos, salvo en el caso de revocación del presidente, para el que se mantuvo la exigencia de mayoría absoluta sobre el total de los electores. Estos cambios propiciaron el despegue de la institución y la activación, entre agosto de 2010 y abril de 2011, de 730 iniciativas de revocatoria dirigidas

27 Castellanos Santamaría, A. S., «Ecuador: la transformación de las reglas del juego y sus consecuencias (1998-2013)», en Y. WELP y U. SERDÜLT (coords.), La dosis hace el veneno. Análisis de la revocatoria del mandato..., op. cit., p. 91. 
en su mayoría contra autoridades locales, pero también contra electos nacionales, incluido un intento de revocatoria de Rafael Correa que no superó la fase de recogida de firmas. Llegaron a ser votadas 78 revocatorias de cargos locales, de los cuales fueron revocados 6 alcaldes, 9 concejales y 6 vocales parroquiales ${ }^{28}$.

La Asociación de Municipalidades presentó ante la Corte Constitucional una acción de inconstitucionalidad por omisión contra la Asamblea Nacional y el Ejecutivo a fin de suspender las revocatorias en marcha y provocar la reforma de la normativa vigente. En respuesta, la Corte dictó la Sentencia N. ${ }^{\circ}$ 001-11SIO-CC, de 26 de enero de 2011, en la que exigió incorporar a la normativa reguladora la fundamentación de la solicitud de revocatoria, el aumento de las firmas requeridas en función de la autoridad y de la circunscripción electoral, la obligatoriedad de notificar a la autoridad para permitirle formular alegaciones y el reforzamiento de la intervención del órgano electoral. Dichas exigencias fueron incorporadas en marzo de 2011 al Reglamento del Consejo Nacional Electoral (CNE) para el ejercicio de la democracia directa a través de la iniciativa popular, consultas populares, referéndum y revocatoria del mandato. Tras su aprobación, el porcentaje de firmas para activar la revocatoria ha pasado a ser variable, desde el diez por ciento en circunscripciones de 300.000 electores hasta el veinticinco por ciento en circunscripciones de 5.000. El plazo para reunirlas se ha reducido en función de la autoridad afectada, a la que debe notificarse y a la que se ha reconocido el derecho a formular alegaciones e impugnar la solicitud. El Reglamento ha atribuido al CNE la potestad para verificar el cumplimiento de los requisitos, juzgar la fundamentación de la revocatoria y decidir sobre las alegaciones e impugnación de la autoridad. A resultas de ello, la revocatoria ha dejado nuevamente de ser, a juicio de alguna doctrina, un derecho de participación en Ecuador ${ }^{29}$. Debido al incremento de los requisitos, las solicitudes de revocación se han reducido y la mayoría de las revocatorias no han llegado a ser votadas, bien por no superar el número de firmas en plazo o no acreditar suficientemente las causas, siendo la última y más significativa de ellas la solicitud presentada en febrero de 2019 por el activista Galo Valarezo contra el presidente Lenín Moreno, cuya fundamentación fue rechazada por el $\mathrm{CNE}^{30}$.

En Venezuela, la institucionalización de la revocación del mandato fue propuesta en 1991 por la Comisión Bicameral de Revisión de la Constitución, pero el proyecto de reforma constitucional resultante fracasó al ser suspendida su discusión

28 Un balance de estas revocatorias en Erazo, L. C. y Chamorro, L., «Democratizando la revocatoria para alcaldes en Ecuador y Colombia: la gobernanza local en la encrucijada», op. cit., pp. 83-86.

29 Ramírez Gallegos, F., «Del vértigo al estancamiento: los procesos revocatorios locales en el Ecuador», en F. Tuesta Soldevilla (ed.), Una onda expansiva: las revocatorias en el Perú y América Latina, op. cit., pp. 147; Castellanos Santamaría, A. S., «Ecuador: la transformación de las reglas del juego y sus consecuencias (1998-2013)», op. cit., pp. 98-99.

30 Las causas alegadas en la solicitud y los argumentos para rechazarlas argüidos por el CNE pueden verse en https://www.planv.com.ec/historias/politica/tres-razones-del-correismo-revocar-el-mandato-lenin-moreno (consultado el 24 de noviembre de 2019). En 2015, el CNE también archivo una segunda solicitud de revocatoria contra Rafael Correa por no quedar suficientemente motivada. 
en el Senado a finales de 1992. La constitucionalización de la figura volvió a plantearse en la campaña de las elecciones presidenciales de 1998 como una de las principales propuestas de Hugo Chávez y de la coalición política que lo apoyaba. Tras su victoria electoral, Chávez impulsó la constitución de una Asamblea Nacional Constituyente y la ratificación en referéndum de la Constitución de 1999, cuyo artículo 72 declara revocables todos los cargos y magistraturas de elección popular y establece las reglas fundamentales para su ejercicio. Conforme a dicho precepto, la solicitud de la revocación no puede plantearse antes del trascurso de la mitad del período para el cual la autoridad es elegida; en el caso del presidente de la República, no antes de tres años de mandato. Concebida como un derecho político, la revocatoria no precisa de justificación para ser activada. La solicitud debe ir avalada por un número de electores no menor al veinte por ciento de los inscritos en la correspondiente circunscripción. Verificado el número de firmas, procede la convocatoria del referéndum, cuya validez depende de la participación de, al menos, un veinticinco por ciento de los inscritos en el padrón de referencia. Para que la revocación del cargo se produzca, el número de votos a favor de la destitución debe ser mayor o igual al número de votos que la autoridad obtuvo en su elección, a fin de garantizar que la representatividad de quienes lo destituyen es al menos equiparable a la de quienes lo eligieron. De fracasar, no cabe otra revocatoria durante el mandato restante. Si prospera, la sustitución de la autoridad ha de realizarse mediante una nueva votación, pero sólo en los casos que la Constitución y el legislador prevén. Los diputados cuyo mandato sea revocado quedan inhabilitados para optar a cargos de elección popular en el período siguiente (art. 198 de la Constitución). De ser revocado el presidente de la República durante el cuarto año de su mandato, deben convocarse elecciones; después del cuarto año, en cambio, será suplido por el vicepresidente ejecutivo y no mediante elección popular (art. 233 de la Constitución).

Reelegido Chávez en julio de 2000 con arreglo a las previsiones de la nueva Constitución, la mitad de su mandato se cumplía en agosto de 2003, momento a partir del cual la revocación era posible. Con ese propósito, la oposición política reunió en febrero de ese año 3,2 millones de firmas, pero su iniciativa se truncó debido a la ausencia de desarrollo de las previsiones constitucionales. Ante el vacío normativo, la Sala Constitucional del Tribunal Supremo de Justicia, en su sentencia 2341/2003, de 25 de agosto, facultó al Consejo Nacional Electoral (CNE) para regular el procedimiento aplicable a la revocación presidencial, lo que el CNE hizo mediante resoluciones e instrucciones ad hoc que configuraron, a juicio de la doctrina, «una compleja madeja de fases y sub-fases y de criterios de validación e impugnación de los diversos aspectos del proceso revocatorio [...], afectando a la seguridad jurídica del proceso y los derechos de las partes, en especial los de los solicitantes de la revocatoria del mandato presidencial» ${ }^{31}$. Las fir-

31 Kornblith, M., «Venezuela: polarización, revocatoria y después», en Y. Welp y U. SerdüLT (coords.), La dosis hace el veneno..., op. cit., pp. 123 y 126. Detalla dicha madeja normativa, DomINGO 
mas ya reunidas fueron invalidadas por su extemporaneidad. Y, en su regulación, el CNE estableció un plazo de firmas de tres días, exigió recogerlas en las oficinas instaladas por el propio CNE con presencia de testigos de ambas partes e introdujo un paso previo a su recogida: la conformación de una agrupación de ciudadanos creada ad hoc que reúna el uno por ciento de adhesiones respecto del padrón o, en su defecto, que la revocatoria sea impulsada por una agrupación política ya constituida, lo que excluyó la promoción de la revocatoria a título individual por los propios ciudadanos ${ }^{32}$.

Siguiendo el nuevo diseño, en noviembre de 2003 la oposición satisfizo el requisito del uno por ciento de adhesiones e impulsó una segunda recogida de firmas y huellas dactilares en las mesas establecidas al efecto, lográndose la cifra de 3,4 millones de peticionarios. Su verificación se prolongó por más de cien días cuando la normativa preveía treinta y, a su término, el CNE declaró que 876.017 firmas eran dudosas y las restantes no llegaban al $20 \%$ exigido por la Constitución ${ }^{33}$. Tras varios recursos y dilaciones, el organismo electoral reconoció finalmente en el período de reparo la existencia de 2,7 millones de firmas válidas y convocó el referéndum, que se celebró el 15 de agosto de 2004. La pregunta fue polémica: la CNE evitó en ella la mención al acto de revocar y se sugirió la ilegitimidad de interrumpir el mandato democráticamente otorgado. Debido a la polarización existente, la participación alcanzó el 69,92\% del censo, el 59,1\% de los votantes se pronunciaron en contra de la revocación y Chávez continuó en el cargo.

También en 2003 se intentó activar la revocatoria del mandato de varios diputados, pero las solicitudes fueron desestimadas porque no existía aún normativa reguladora aplicable a dichos procesos y se detectaron irregularidades en la recolección de firmas. En octubre de 2007, la CNE aprobó, mediante Resolución N. ${ }^{\circ} 070906-2770$ del 6 de septiembre de 2007, las Normas para regular el procedimiento de promoción y solicitud de referendos revocatorios de mandatos de cargos de elección popular y, a su amparo, se presentaron 167 solicitudes de revocatoria, de las cuales sólo 10, que afectaron a dos alcaldes y una legisladora del Estado de Amazonas, a dos alcaldes del Estado de Cojedes y a varios alcaldes en los Estados de Bolívar, Falcón, Guárico, Miranda y Portuguesa, llegaron a las urnas. Tras dichas revocatorias, sin embargo, la práctica de la institución ha languidecido, limitada por las numerosas trabas de su regulación. En abril de 2016

BARbERÁ, E., «Revocación del mandato presidencial en Venezuela: instrumento controvertido en su sistema presidencial», Teoría y Derecho: revista de pensamiento jurídico, n. ${ }^{\circ}$ 25, 2019, pp. 60-62.

32 Un análisis de este procedimiento y del papel jugado por la Corte Constitucional del Tribunal Supremo de Justicia en la normalización de la CNE como legislador electoral, en MATHeus Brito, D., «La regulación del referendo revocatorio de mandato en Venezuela y en Colombia», op. cit., pp. 4-17.

33 El aspecto más cuestionado del proceso fue, sin embargo, la divulgación de los nombres y datos de los electores firmantes en la página web del diputado chavista, Luis Tascón, lo que pervirtió la garantía del sufragio secreto. Véanse Kornblith, M., «Venezuela: polarización, revocatoria y después», op. cit., pp. 118120; Eberhardt, M. ${ }^{a}$ L., «La revocatoria presidencial en América Latina. Ventajas y limitaciones. Los casos de Venezuela, Bolivia y Ecuador», op. cit., pp. 121-123. 
se intentó activar un nuevo proceso de revocación del presidente, en esta ocasión dirigido contra Nicolás Maduro, pero la fase de recogida de firmas fue suspendida por el CNE el 20 de octubre a resultas de las decisiones de los tribunales penales de Aragua, Carabobo, Monagas, Apure y Bolívar, que ordenaron posponer cualquier acto derivado del acopio de manifestaciones de voluntad que apoyaran la revocatoria por indicios de fraude ${ }^{34}$. Y el 10 de noviembre de 2016, la Sala Electoral del Tribunal Supremo rechazó la solicitud de amparo presentada por la oposición para reanudar el proceso de recogida de firmas suspendido. Entre tanto, la Asamblea Nacional, de mayoría opositora, pretendió dotar a la revocatoria de una nueva regulación mediante el proyecto de Ley orgánica de referendos, aprobado el 21 de abril de 2016, pero la iniciativa fue abandonada. Truncada la vía institucional para promover la revocación del presidente, la contestación se trasladó a las calles, en lo que parece ser una constante en la crisis de los presidencialismos de los principales países andinos.

Bolivia fue el tercer país de la región en constitucionalizar y extender la revocación del mandato a todas las autoridades electas. Lo hizo en 2009, pero tras un singular proceso que llevó a regular la institución y a celebrar un referéndum de revocación del presidente Evo Morales, su vicepresidente, Álvaro García Linera, y ocho de los nueve prefectos departamentales antes de aprobarse el texto constitucional. La idea de celebrar este referéndum revocatorio surgió en el contexto de las intensas protestas que suscitaron los trabajos de la Asamblea Nacional Constituyente. A fin de superar el conflicto y la falta de legitimidad que la oposición achacaba al proceso constituyente, el presidente Morales y su vicepresidente ofrecieron someter a revocatoria su mandato. Los prefectos de varios departamentos también se mostraron dispuestos a ello y Poder Democrático Social, principal partido de oposición, aceptó debatir en el Congreso un proyecto de ley ad hoc que regulara las revocatorias. La Ley fue aprobada el 12 de mayo de 2008 y el referéndum tuvo lugar el 8 de agosto, sin movilización ni recogida de firmas, puesto que el proceso no se activó a iniciativa popular, sino desde las propias instituciones. Tras su celebración, el presidente y el vicepresidente se mantuvieron en el cargo, lo mismo que seis de los ocho prefectos: los dos oficialistas de los departamentos de Oruro y Potosí y los cuatro pertenecientes a la oposición de los departamentos de Tarija, Santa Cruz, Pando y Bendi. Fueron revocados, en cambio, los prefectos opositores de La Paz y Cochabamba ${ }^{35}$.

34 Según Hernández, J. L., las decisiones de los tribunales penales no tenían por qué incidir en la suspensión del procedimiento revocatorio, puesto que la CNE ya había realizado las comprobaciones oportunas y ya fueron anuladas las firmas que no cumplían con los requisitos de validación. La eventual existencia de fraude en firmas concretas exigía investigar su autoría, pero no invalidar un proceso electoral. Los tribunales penales se extralimitaron, al igual que la CNE al suspender el proceso. Cfr. «La violación del derecho al referendo revocatorio presidencial en Venezuela», Revista de la Facultad de Derecho de México, n. ${ }^{\circ}$ 67, LXVII, 2017, pp. $913-814$.

35 Una crónica de estas consultas en Eberhardt, M. ${ }^{a}$ L., «La revocatoria presidencial en América Latina. Ventajas y limitaciones. Los casos de Venezuela, Bolivia y Ecuador», op. cit., pp. 124-127. 
Meses más tarde, la revocatoria fue reconocida en la nueva Constitución, ratificada en referéndum en enero de 2009. En 2010, se aprobó la Ley N. ${ }^{\circ} 26$ de 30 junio, del Régimen Electoral (LRE), y en 2013, el Tribunal Superior Electoral aprobó, mediante Resolución N. ${ }^{\circ}$ 139/2013, de 19 de junio, el Reglamento para la verificación de huellas, firmas y la pregunta en el proceso de iniciativa popular de revocatoria de mandato. Pero, al igual que en Ecuador y Venezuela, la regulación constitucional ha resultado constreñida por un severo desarrollo normativo que ha puesto en evidencia la distancia existente entre la retórica participativa y su cicatera concretización.

La Constitución y la LRE coinciden al extender la revocación a todas las autoridades electas a nivel nacional, departamental, regional o municipal a partir de solicitudes provenientes de iniciativas ciudadanas. Dichas solicitudes no precisan alegar causa alguna y sólo pueden presentarse una vez en cada mandato, transcurrida la mitad del mismo y antes del último año de gestión. La Constitución y la LRE difieren, sin embargo, en punto a los porcentajes de firmas requeridos para activar el procedimiento: mientras la Constitución sólo exige que la solicitud sea avalada por el quince por ciento de electores censados en la circunscripción, la LRE incrementa los porcentajes y los diferencia por autoridades y niveles de gobierno sin que ello haya dado lugar al cuestionamiento de su constitucionalidad. Para las autoridades nacionales, departamentales y regionales, las firmas y huellas dactilares deben superar al menos el veinticinco por ciento del padrón correspondiente. Para las autoridades municipales, el treinta por ciento. Adicionalmente, para las autoridades nacionales, departamentales y regionales se exige que esas adhesiones superen, respectivamente, el veinte por ciento en cada uno de los departamentos, el veinte por ciento en cada provincia y el veinticinco por ciento en cada municipio de la región. Y trascurrido el plazo de noventa días de recogida de firmas y de sesenta días de verificación, el Tribunal Electoral debe remitir a la Asamblea Legislativa Plurinacional la iniciativa para que ésta apruebe, nada menos que mediante ley, por mayoría absoluta, la convocatoria del referéndum revocatorio. La validez de la consulta requiere una participación superior al cincuenta por ciento más uno de los inscritos en la respectiva circunscripción. Y la revocación depende de la existencia de una mayoría simple de votos a favor y de que su número y porcentaje sea superior al número y porcentaje de votos con los que la autoridad fue elegida ${ }^{36}$.

El 6 de diciembre de 2009 los bolivianos eligieron al presidente, al vicepresidente y a setenta diputados uninominales y el 4 de abril de 2010 a 2.394 autoridades locales, entre gobernadores, asambleístas, alcaldes y concejales. La duración

36 Un análisis de la regulación de la revocatoria en Verdugo SiLva, J. T., «Bolivia: entre la expectativa de uso y los intentos fallidos de activación», en Y. WELP y U. SERdüLT (coords.), La dosis hace el veneno..., op. cit., pp. 143-144; AsCarrunZ, J. y Welp, Y., «La revocatoria de mandato en Bolivia. Análisis de limitaciones y propuestas de reforma». Documentos de análisis 01/2019. Red Nacional de Participación Ciudadana y Control Social, 2019, pp. 5-10. 
del mandato de todas estas autoridades es de cinco años. Y como la revocatoria sólo puede plantearse transcurrida la mitad del mandato y antes del último año de su término, ha habido desde entonces dos ciclos habilitados para solicitarla. En el primero, que se abrió en 2013 , se presentaron un total de 124 solicitudes de revocación contra 216 autoridades de diferentes niveles de gobierno. 79 solicitudes fueron habilitadas para la recolección de firmas, pero sólo tres reunieron el número suficiente para ser consideradas. En la fase de verificación, sin embargo, el Tribunal Supremo Electoral declaró que ninguna cumplía los requisitos para continuar el proceso. En el segundo ciclo, que se abrió en 2018, las solicitudes de revocatoria se duplicaron hasta alcanzar las 245 , de las cuales 16 fueron desistidas, 62 resultaron rechazadas por el órgano electoral plurinacional y 168 fueron habilitadas para la recolección de firmas. Tras un mar de desistimientos de los promotores, incumplimientos de plazos e insuficiencia de firmas, tan sólo una de ellas, la dirigida contra el alcalde de Bolpedra (Pando), pudo culminar el proceso al reunir las firmas necesarias. La votación, convocada mediante ley por la Asamblea Legislativa Plurinacional, se celebró el 17 de febrero de 2019, pero la participación no superó el cincuenta por ciento de electores requerido en el artículo $30 \mathrm{LRE}$, por lo que la consulta no fue válida y el alcalde continuó en su cargo. En suma, de 369 solicitudes de revocatoria presentadas en ambos ciclos, ninguna ha prosperado. Los porcentajes de firmas han resultado ser demasiado elevados, los plazos del proceso, perentorios, y el umbral de participación y la doble mayoría exigida para revocar, excesivos. El balance de la revocatoria en Bolivia no ha podido ser, por tanto, más desalentador.

\section{LA REVOCACIÓN DE MANDATOS DE LAS AUTORIDADES EJECUTIVAS EN MÉXICO TRAS LA REFORMA CONSTITUCIONAL DE 2019}

En México, la revocación del mandato se introdujo en Yucatán en 1938 bajo una modalidad mixta, a instancia ciudadana aprobada por la Legislatura, pero nunca fue activada. Entre 1997 y 2018, la revocatoria propiamente dicha, a iniciativa y por decisión de los electores, fue regulada en las constituciones de Chihuahua (art. 27), Zacatecas (arts. 14 y15), Oaxaca (arts. 23 a 25), Morelos (art. 19 bis), Aguascalientes (art. 17), Guerrero (arts. 19 y 128) Jalisco (art. 11.VIII), Nuevo León (art. 63) y Ciudad de México (art. 25). A nivel federal, las iniciativas para su constitucionalización se han sucedido desde 2009. En la LXI Legislatura varios diputados del Partido del Trabajo (PT), del Partido Revolucionario Institucional (PRI) y del Partido de la Revolución Democrática (PRD) presentaron hasta seis iniciativas de reforma constitucional que pretendían el reconocimiento como derecho de la revocación de mandato, regulando directamente las bases de su ejercicio o encomendando su regulación al legislador. Una de dichas iniciativas detallaba el procedimiento para la revocación del presidente de la República, 
los diputados y los senadores y otra, además, extendía la revocación a los gobernadores de los estados, el jefe de gobierno del Distrito Federal, los presidentes municipales y los titulares de los órganos político-administrativos de las demarcaciones territoriales del Distrito Federal. En la LXII Legislatura se tramitaron hasta diez iniciativas con idéntico objeto, nueve presentadas por diputados de PRD, Movimiento Ciudadano (MC), Partido de Acción Nacional (PAN) y Movimiento Regeneración Nacional (Morena) y una por el Congreso de Jalisco, algunas de las cuales destacaron por la amplitud de los cargos revocables y la minuciosa regulación de los procesos revocatorios. Y lo mismo puede decirse de las iniciativas presentadas en la LXIII Legislatura por varios diputados de Morena, PRD, MC y por el Congreso de Morelos ${ }^{37}$. Ninguna de ellas prosperó.

Durante la campaña de las elecciones federales de 1 de julio de 2018, en las que se renovaron ambas cámaras del Congreso y la Presidencia de la República, el candidato presidencial, López Obrador, y su partido Morena prometieron constitucionalizar la revocación del mandato del cargo de presidente de la República e impulsar las reformas constitucionales necesarias para extender la institución a los gobernadores de todas las entidades federativas a fin de evitar la inseguridad jurídica generada tras las sentencias de la Suprema Corte de Justicia de la Nación 21/2012 (10a.) y 28/2013 (9a.) anteriormente citadas, que declararon las regulaciones de la revocatoria de Yucatán y Chihuahua contrarias al orden constitucional federal.

Con ese objeto, diputados de Morena presentaron en septiembre y octubre de 2018 sendas iniciativas de reforma constitucional en materia de revocación de mandato. Y a ellos se sumaron diputados del PRI y del PRD con iniciativas propias, cuyo estudio e integración realizó la Comisión de Puntos Constitucionales de la Cámara de Diputados ${ }^{38}$. El 14 de marzo de 2019 el Pleno de la Cámara aprobó su dictamen con 329 votos a favor, 153 en contra y 2 abstenciones, en el que se incorporaba la figura de la revocación del mandato presidencial a iniciativa del propio presidente, del equivalente al treinta y tres por ciento de los integrantes de cualquiera de las cámaras del Congreso o a iniciativa ciudadana de, al menos, el tres por ciento de los inscritos en la lista nominal de electores; y en el que, asimismo, se instaba a las entidades federativas a regular la revocación de sus gobernadores. En el caso del presidente, la votación debería realizarse a mitad del mandato, el mismo día de la jornada electoral en que se eligen diputados federales. Y en el caso de los gobernadores, durante el tercer año del período para el que fueron designados.

37 Un análisis sistemático de estas iniciativas de reforma constitucional en materia de revocación, en Gamboa Montejano, C. y Ayala Cordero, A., Revocación de mandato. Estudio comparativo a nivel local e internacional, $y$ de iniciativas presentadas en el tema, op. cit., pp. 47-104.

38 Sobre las iniciativas presentadas en la LXIV Legislatura y el dictamen de la Comisión de Puntos Constitucionales, Zamora SÁENZ, I., «La discusión legislativa sobre revocación de mandato en la LXIV Legislatura», Mirada Legislativa, n. ${ }^{\circ}$ 169. Senado de la República, México, 2019, pp. 1-9. 
El dictamen de la Comisión suscitó diversas críticas. La revocatoria a instancias del presidente parecía ser más un plebiscito de ratificación que un instrumento de rendición de cuentas. La atribución de la iniciativa a los parlamentarios tampoco se compadecía con la naturaleza y función de la revocatoria. Y celebrar en la misma jornada la consulta de revocación y las elecciones parlamentarias podía distorsionar ambas votaciones. El proyecto, además, no concretaba cómo sería sustituido el presidente en el supuesto de ser revocado, ni el momento en que podría implementarse por primera vez el procedimiento revocatorio. Debido a ello, en la tramitación subsiguiente se introdujeron cambios significativos en el proyecto constitucional. La iniciativa de la revocación del mandato presidencial quedó reservada a los ciudadanos en un número equivalente, al menos, al tres por ciento de los inscritos en la lista nominal de electores. La coincidencia entre la consulta revocatoria y los procesos electorales fue excluida. Y se reguló el procedimiento de sustitución en el cargo, así como el momento de activar, en su caso, la primera revocatoria presidencial. El nuevo dictamen fue aprobado por el Pleno del Senado con 98 votos a favor, 22 en contra y ninguna abstención. La Cámara de Diputados asumió las modificaciones el 5 de noviembre de 2019, tras lo cual el texto fue enviado a las legislaturas estatales para su análisis y ratificación. Satisfecho el trámite, el Decreto fue publicado en el Boletín Oficial de la Federación el 20 de diciembre de 2019.

Tras la entrada en vigor de la reforma, la participación en los procesos de revocación es considerada un derecho ciudadano (art. 35 IX de la Constitución) y, consecuentemente, no resulta preciso alegar causa alguna para instarla. Conforme a la nueva redacción de los artículos 116 y 122.III de la Constitución, las entidades federativas deben garantizar el derecho a solicitar la revocación del mandato de su autoridad ejecutiva. A tal efecto, han de reformar sus constituciones en el plazo de dieciocho meses desde la entrada en vigor de la reforma constitucional, y las entidades que ya regulaban la institución deben armonizar su régimen jurídico a las bases establecidas en la Constitución federal, donde se prescribe que la revocación podrá plantearse durante los tres meses posteriores a la conclusión del tercer año de mandato por un número equivalente, al menos, al diez por ciento de la lista nominal de electores de la entidad federativa y en la mitad más uno de los municipios o alcaldías que la integran. La votación deberá celebrarse en fecha posterior y no coincidente con los procesos electorales o de participación ciudadana locales o federales. Y su resultado será vinculante si la participación supera el cuarenta por ciento de la lista nominal de electores y si la mayoría absoluta de los votantes es favorable a la revocación.

La revocación del presidente de la República podrá solicitarse durante los tres meses posteriores al término del tercer año de mandato. El Instituto Nacional Electoral (INE) verificará que la solicitud ha sido avalada por, al menos, el tres por ciento de los inscritos en la lista nominal de electores, debiendo superarse ese porcentaje en diecisiete entidades federativas. La votación deberá celebrarse el domingo siguiente a los noventa días posteriores a la convocatoria y en fecha no 
coincidente con las jornadas electorales, federal o locales. La revocación se producirá si la mayoría absoluta de los votantes se pronuncian en contra de la continuidad del presidente y si la participación supera el cuarenta por ciento de los inscritos en la lista nominal. De ser así, la titularidad del Poder Ejecutivo la asumirá provisionalmente quien ocupe la Presidencia del Congreso; $y$, dentro de los treinta días siguientes, el Congreso designará, por una mayoría calificada de dos terceras partes de sus miembros, al sustituto del presidente depuesto (art. 84 de la Constitución).

Pese a haberse constitucionalizado un año después del inicio de su mandato, el transitorio cuarto de la Constitución prevé que la revocatoria pueda activarse contra el presidente López Obrador. La recogida de firmas podrá realizarse del 1 de noviembre hasta el 15 de diciembre de 2021. De reunirse las firmas requeridas, el INE convocará la consulta dentro de los veinte días siguientes al vencimiento del plazo y la votación tendrá lugar sesenta días después, esto es, en febrero o marzo de 2022. Así las cosas, y teniendo en cuenta el reducido porcentaje de ciudadanos exigido para activar la revocatoria, es posible que la implementación de la institución en México se produzca también à la grande orchestre, al afectar, antes que a ninguna otra autoridad, al primer mandatario de la República. El tiempo dirá si las expectativas generadas por la introducción de la revocación del mandato se ven satisfechas. Y si su desarrollo legislativo, al que el constituyente remite en varios puntos, facilita o no su ejercicio y garantiza los derechos de todos, incluida la igualdad de oportunidades en campaña.

\section{BALANCE COMPARADO Y CONSIDERACIONES FINALES}

Hasta hace apenas tres décadas, la revocación del mandato era un instrumento de democracia directa que apenas había trascendido fuera de EE.UU. y Suiza. La crisis de la representación y del sistema de partidos que padecieron varios países latinoamericanos en los años ochenta del pasado siglo condujo, sin embargo, a reparar en la revocación del mandato como un instrumento adicional de participación y control de los ciudadanos que podría estimular la receptividad y la responsabilidad de los cargos electos en el ejercicio de su mandato.

En 1991, Colombia incorporó en su nueva Constitución una gran variedad de mecanismos de participación política, entre ellos la revocación del mandato, que el legislador limitó a las autoridades locales. Perú la constitucionalizó dos años más tarde, en un contexto caracterizado por el desprestigio de los partidos tradicionales. En Argentina, la recuperación de la democracia supuso la extensión de la revocatoria del mandato a nuevas provincias y a la Ciudad Autónoma de Buenos Aires, que la regularon en sus constituciones y en las leyes y cartas orgánicas municipales. En 1998, Ecuador reguló la revocación de diputados, prefectos y alcaldes y la Constitución de 2008 extendió la institución a todos los cargos de elección popular, incluido el presidente. En Venezuela, el colapso del sistema 
de partidos abonó el terreno para la introducción de la revocación del mandato en la Constitución de 1999 y determinó su extensión a todas las autoridades electas. Cinco años más tarde, el presidente Chávez superaba el primer proceso revocatorio. En 2004, Panamá reconoció la revocación del mandato de los diputados de libre postulación a iniciativa y por decisión de los ciudadanos y amplió la revocación por decisión de los partidos a las autoridades locales. En 2008, Bolivia apostó por regular ad hoc el referéndum revocatorio del mandato del presidente, del vicepresidente y de ocho de los nueve prefectos, y, celebrado éste, reguló la institución en la Constitución de 2009. En diciembre de 2019, finalmente, México ha reformado su Constitución federal para regular la revocación del presidente de la República y extender la revocatoria a las autoridades ejecutivas de los entes federados.

A expensas de lo que pueda ocurrir en México, donde acaba de regularse, el balance provisional que cabe hacer sobre la funcionalidad y el rendimiento alcanzado por la revocación del mandato en América Latina es desigual y mayoritariamente insatisfactorio. Con la excepción del caso peruano, en que se han activado miles de revocatorias de sus autoridades locales, y el breve lapso en que la institución despegó en Ecuador merced a la flexibilización de sus requisitos, lo cierto es que en la región se han implementado escasas iniciativas de revocación, muy pocas han llegado a las urnas y menos aún han concluido con la destitución de la autoridad cuestionada.

En Colombia la revocación del mandato se ha visto lastrada por su restrictiva regulación. Las leyes 741 de 31 de mayo de 2002 y 1757 de 6 de julio de 2015 han reducido el porcentaje de firmas para solicitarla, eliminado el requisito de que los firmantes debían haber participado en la elección del mandatario y reducido el umbral de participación. Las reformas, sin embargo, han tenido escaso efecto debido a la instrumentación de las revocatorias con fines puramente electores y a la baja participación ciudadana. En Argentina, sólo la provincia de Chaco y la Ciudad Autónoma de Buenos Aires han sancionado las leyes necesarias para hacer uso de la institución, pero sus requisitos son muy elevados, por lo que ninguna revocatoria ha prosperado a nivel provincial. En el ámbito municipal, donde la regulación es más flexible, los intentos de revocación han sido frenados en los tribunales mediante sendos recursos de los intendentes afectados, quienes, alegando indefensión, han judicializado el procedimiento revocatorio, alterado su naturaleza política y frustrado su alcance. En los Estados mexicanos que introdujeron la institución, no se ha activado ninguna revocatoria a causa de la inseguridad jurídica resultante de las declaraciones de inconstitucionalidad de la revocación del mandato en Yucatán y Chihuahua. En Panamá, la modalidad de revocación de los representantes a instancias de los partidos que los postularon ha resultado problemática y, desde su incorporación en 2004, la revocación de autoridades de libre postulación a iniciativa y por decisión popular se mantiene inédita. Venezuela y Bolivia comparten haber implementado sendos procesos revocatorios contra las máximas autoridades ejecutivas de la Nación en un contexto de extrema polarización. Pese a estas experiencias, que deberían haber allanado la práctica de la revocatoria en ambos países, la 
institución se encuentra seriamente cuestionada por las dificultades que los organismos electorales han introducido en los procedimientos revocatorios. En Venezuela, el CNE ha configurado una maraña de trámites que impiden su ejercicio, y en Bolivia la institución no ha funcionado en ninguno de los dos ciclos en que ha sido posible su activación (2013 y 2018) debido a los perentorios plazos y a la doble mayoría exigida.

Ecuador y Perú constituyen la excepción al panorama descrito. En Ecuador, la Ley Orgánica 175/2010, de 20 abril, redujo el umbral de firmas, amplió los plazos para recogerlas y eliminó la necesidad de fundamentar la solicitud. Ello posibilitó el despegue de la institución, pero la reacción de las autoridades afectadas y la intervención de la Corte Constitucional ha dado lugar al endurecimiento de los requisitos y los controles, de suerte que las revocatorias han disminuido sensiblemente. En Perú, la laxitud regulatoria y el incentivo del adelanto electoral en caso de ser revocados más de un tercio de los miembros de las corporaciones propiciaron la presentación de miles de solicitudes y la revocación de 1.739 representantes municipales. Ello generó déficits de legitimidad y gobernabilidad en numerosos municipios, lo que ha dado lugar en 2015 a un replanteamiento normativo de la revocatoria a fin de reducir los incentivos electorales y adecuar su uso a las funciones de accountability y control ciudadano que le son propias.

La revocación del mandato no es la panacea y plantea algunos problemas. La revocación puede alterar los fundamentos de la representación política y del mandato libre, especialmente si se abusa de ella trivializando su alcance o se amenaza reiteradamente con su activación, lo que condiciona las decisiones de las autoridades electas ${ }^{39}$. Impulsada desde las propias autoridades, su utilización plebiscitaria es prácticamente segura; activada desde abajo, su uso excesivo puede desencadenar inestabilidad institucional e ingobernabilidad. Ello explica, allí donde la institución se regula, los candados, restricciones y agravantes que normalmente se oponen para su ejercicio. La revocación del mandato puede ser, con todo, un instrumento democrático útil. La revocación puede favorecer la receptividad de los representantes y estimular un contacto más estrecho entre estos y sus representados. Es un instrumento de rendición de cuentas y control político que incentiva la responsabilidad de las autoridades, su representatividad y su compromiso hacia la palabra dada. Y por el lado de los ciudadanos, estimula su interés y atención hacia la acción de gobierno, facultándoles de manera reglada para expresar su descontento y actuar de contrapeso ${ }^{40}$. Los juicios políticos previstos en los sistemas presidenciales enfrentan múltiples resistencias legales y políticas, tardan demasiado y rara vez se actualizan. La revocación, en cambio, es más flexible y no precisa fundamentos jurídicos. Su institucionalización opera como una

39 Por todos, Aragón Reyes, M. y López González, J. L., «Revocatoria de mandato», Diccionario Electoral, Tomo II, Instituto Interamericano de Derechos Humanos, San José de Costa Rica, 2000, pp. 1141-1142.

40 García Campos, A., «La revocación del mandato: un breve acercamiento teórico», op, cit., p. 25. 
válvula de seguridad del sistema político que puede evitar que los conflictos se enconen y sus protagonistas aspiren a buscar salidas fuera de los cauces institucionales $^{41}$, algo en absoluto desdeñable teniendo en cuenta los estallidos populares y las intervenciones militares que las democracias latinoamericanas han padecido.

Para que la revocatoria pueda desempeñar estas funciones, las democracias de América Latina deben mejorar sus diseños institucionales. Es obvio que los elevados porcentajes de firmas para solicitarla y los umbrales de participación exigidos para conferir validez a la votación dificultan, cuando no impiden, su utilización, especialmente en países como Colombia o Bolivia, donde la participación electoral es baja. Dichos porcentajes y umbrales responden a la consideración de que alcanzar la mayoría de votos en torno a la deposición de un representante es más fácil que construirla en torno a su elección, pero su efecto en no pocas ocasiones es el mantenimiento en el cargo de autoridades que quedan descalificadas por la mayoría de los votantes, lo que debilita su legitimidad e incrementa la polarización. Dichos requisitos deberían reducirse, compensándose mediante la elevación de las mayorías requeridas para revocar, equiparándolas a las obtenidas por las autoridades en su elección. La ampliación del plazo para recoger las firmas que avalen la revocatoria es otro aspecto que favorece su activación. En un extremo, Perú no fijaba plazo; en el extremo opuesto se halla Venezuela, donde el plazo para firmar es tan sólo de tres días y ha de hacerse en las oficinas instaladas por el CNE con presencia de testigos de ambas partes, lo que dificulta su recogida. Las causas para activar la revocatoria deberían ser de naturaleza política, como la pérdida de confianza, la insatisfacción general o el incumplimiento del programa, no otras, y, conforme a su naturaleza, no puede exigirse su prueba, ni ser revisada su fundamentación. Consecuentemente, los órganos electorales deberían verificar el cumplimiento de los requisitos formales, no evaluar la procedencia de la revocatoria ni juzgar las causas, como se hace en Colombia y Ecuador. Y, por el mismo motivo, debe evitarse la judicialización, porque a los tribunales corresponde verificar la legalidad del proceso, pero no su fundamentación, ni su oportunidad. A diferencia del juicio político, la revocación del mandato se decide en las urnas por el mismo cuerpo electoral que designó al cargo y no exige las garantías del debido proceso ${ }^{42}$. En la revocación se pone a prueba la relación de confianza entre el representante y los electores, no se dilucida la violación de una norma jurídica. Por ello, el ejercicio de la revocatoria, satisfechos los requisitos, no puede generar indefensión.

A tenor de la tendencia a su generalización, la revocación del mandato parece haber llegado a América Latina para quedarse como instrumento adicional de legitimación política e inclusión de la ciudadanía. Debe hacerlo, sin embargo,

41 Sobre la funcionalidad de la revocación del mandato, Cronin, T. E., Direct Democracy. The Politics of Initiative, Referendum and Recall, op. cit., p. 134-138; Zimmerman, J. F., The Recall: Tribunal of the People, op. cit., p. 136.

42 García Campos, A., «La revocación del mandato...», op. cit., pp. 32-34. 
mejorando sus diseños institucionales, reduciendo los umbrales de firmas y de participación requeridos, reforzando sus garantías y la independencia de los órganos electorales e implementando códigos de buenas prácticas en los que la posible manipulación del proceso sea limitada mediante un efectivo sistema de checks and balances. A tal efecto, los actores políticos deben renunciar a los malos usos arraigados en algunos países y los legisladores nacionales deben inspirarse en las regulaciones, las garantías y las prácticas consolidadas del mejor derecho constitucional comparado. El éxito de la revocación del mandato depende en gran medida de ello. Entre tanto, conviene extremar la cautela y disminuir el optimismo. La revocación tardó décadas en arraigar en los EE.UU. Su normalización en las democracias de América Latina llevará también su tiempo. Y posiblemente alguna frustración.

$* * *$

\section{TITLE: The Recall in Latin American Democracies}

ABSTRACT: The recall was, until recent decades, a tool of direct democracy that was hardly known or used outside the United States. However, the crisis of representation and of the party system that several Latin American countries suffered led to recover the recall as an additional form of citizen participation and control that could boost receptivity and responsibility of elected authorities. In only three decades, the recall has moved from being barely known to spreading to the most important Latin American countries and becoming one of the distinctive features of the region. In this work we present a comparative study of the recall in Argentina, Colombia and the Republic of Peru, where it was limited to regional and local authorities. We also analyse the recall of local legislators and authorities by decision of the political parties and popular vote in Panama; the recall in Ecuador, Venezuela and Bolivia, where this institution has spread to all elected offices, including the president of the republic; and the recall of the president and governors of the federal entities of Mexico after the constitutional reform promoted by López Obrador. This work ends by assessing the institutional designs of the recall, where we emphasize the tension between draft legislation and its conditions for implementation.

RESUMEN: La revocación del mandato ha sido, hasta hace unas décadas, un mecanismo de democracia directa poco extendido y apenas usado fuera de EE.UU. La crisis de la representación y del sistema de partidos que padecieron varios países latinoamericanos condujo, sin embargo, a reparar en la revocación del mandato como una vía adicional de participación y control de los ciudadanos que podría estimular la receptividad y la responsabilidad de las autoridades electas. Y de ser una institución apenas conocida, la revocación se ha extendido a varios de los países latinoamericanos más importantes, al punto de convertirse en una de las señas distintivas de la región. En este trabajo se realiza un estudio comparado de la revocación del mandato en Argentina, Colombia y Perú, donde se ha limitado a las autoridades regionales y locales. Se analizan, asimismo, la revocación de los diputados y autoridades locales por decisión de los partidos y a iniciativa y votación popular en Panamá; la revocación en Ecuador, Venezuela y Bolivia, donde la institución se ha extendido a todos los cargos electos, incluido el presidente de la República; y la revocación del presidente y de los gobernadores de los entes federados en México tras la reforma constitucional impulsada en 2019 por López Obrador. El trabajo concluye con un balance de los diseños institucionales de la revocación del mandato, en el que se subraya la tensión existente entre el proyecto normativo y sus condiciones de realización.

KEY WORDS: fundamental rights, human rights, comparative constitutional law, Ireland.

PALABRAS ClAVE: recall, direct democracy, citizen participation.

FECHA DE RECEPCIÓN: 09.01.2020 FeCHA DE ACEPTACIÓN: 26.01.2021 
